\title{
Childhood Gliosarcoma
}

National Cancer Institute

\section{Source}

National Cancer Institute. Childhood Gliosarcoma. NCI Thesaurus. Code C114968.

A gliosarcoma that occurs during childhood. 